\title{
Effect of adding dexmedetomedine, ketamine and their combination to bupivacaine in thoracic epidural on post-operative analgesia in patients undergoing modified radical mastectomy.
}

\section{1- Prof. Dr Hany Ahmed Ibrahim Elmorabaa}

Professor of anesthesia, ICU, and pain relief, faculty of medicine, Assiut University.

E-mail: Elmorabaa@yahoo.com

Telephone number: 01005203980

2- Prof. Dr. Ashraf Amin Mohammed

Professor of anesthesia, ICU, and pain relief, South Egypt Cancer Institute, Assiut University.

E-mail: ashrafkena@yahoo.com

Telephone number: 01153131503

3- Dr. Shereen Mamdouh Kamal

Lecturer of anesthesia, ICU, and pain relief, South Egypt Cancer Institute Assiut University.

E-mail: sheridouh79@yahoo.com

Telephone number: 01006279209

\section{4- Ibtesam Mohammed Abed El Razik}

Resident of Anesthesiology, intensive care and pain relief South Egypt Cancer Institute, Assiut University.

E-mail: ibtesammahamedaz@gmail.com

Telephone number: 01097054074

\section{5- Prof. DR. Mohamed Farouk Mohamed}

Assistant professor of anesthesia, ICU and pain management, South Egypt Cancer Institute, Assiut

University.

E-mail:mfaroukma@gmail.com

Telephone number: 01093942354

published at 24/6/2018 


\begin{abstract}
:
Background: Breast surgery is one of the most common forms of surgery conducted in hospitals; even relatively minor breast surgery can be associated with significant postoperative pain. Opioid administration remains the mainstay of postoperative pain relief, but it can result in significant adverse effects including sedation, nausea, vomiting urinary retention, respiratory depression, delayed recovery of colonic mobility, and prolonged postoperative ileus.
\end{abstract}

Objective: To investigate the efficacy and safety of adding dexmedetomedine, ketamine and their combination as adjuvant analgesic with bupivacaine in thoracic epidural analgesia (TEA) on post mastectomy pain, detection of total dose of IV morphine consumption and time for the first request of rescue analgesia.

Design: Prospective, randomized, double-blinded clinical trial.

Setting: Academic medical center.

Methods: Eighty patients were randomly allocated to receive at T4-5 interspace thoracic epidural analgesia 15 minutes -before general anesthesia (GA)- either $12 \mathrm{ml}$ of hyperbaric bupivacaine $0.125 \%$ plus mixture of 0.3 $\mathrm{mg} / \mathrm{kg}$ ketamine and $0.1 \mu \mathrm{g} / \mathrm{kg}$ dexmedetomedine (DK group) \& $12 \mathrm{ml}$ of hyperbaric bupivacaine $0.125 \%$ plus 0.5 $\mathrm{mg} / \mathrm{kg}$ ketamine (K group) $\& 12 \mathrm{ml}$ of hyperbaric bupivacaine $0.125 \%$ plus $1 \mu \mathrm{g} / \mathrm{kg}$ dexmedetomedine (D group) while the control group received $12 \mathrm{ml}$ of hyperbaric bupivacaine $0.125 \%$ (C group). Post-operative patients were admitted to surgical ICU-for 48 hours for initiation of post-operative analgesia regimen and monitoring of hemodynamics, pain score, time to first request of analgesia, total patient controlled analgesia (PCA) morphine consumption and adverse effects.

Results: Time to first request of analgesia was the longest in DK group as no one asked for analgesia during the first 48 hours, while it was longer in K group ( $37.45 \pm 3.12 \mathrm{~h}$ ) compared to D group $(19.43 \pm 1.78)$ and the control group (13.47 $\pm 1.43 \mathrm{~h})$.

-PCA morphine consumption was less in K group $(4.66 \pm 1.00 \mathrm{mg})$ compared to D group $(6.74 \pm 0.70 \mathrm{mg}) \mathrm{and}$ control group $(8.33 \pm 1.63 \mathrm{mg})$, while DK group did not receive PCA morphine.DK group showed lower postoperative pain scores.

Conclusion: the combination of both dexmedetomedine and ketamine added to bupivacaine in TEA in patients undergoing MRM provided superior postoperative analgesia, prolonged the time to first request of analgesia, and reduced the total consumption of PCA morphine, without serious side effects compared to either drug alone.

\title{
Clinical trial registration: NCT03063671
}

Key words: TEA, dexmedetomedine, ketamine, Breast cancer surgery.

\section{Background:}

Breast cancer is the most frequent tumor in women. The incidence of breast cancer, as well as the need of surgical treatment has increased probably due to increased awareness and improved diagnostic tools resulting in early diagnosis and favorable surgical outcome ${ }^{[1]}$.

Conventionally general anesthesia is the most frequently used technique, but it is associated with inadequate pain control due to lack of residual analgesia and also with other 
complications such as nausea and depression of the immune system ${ }^{[2]}$.

Adequate postoperative analgesia attenuates stress response and prevents unnecessary patient discomfort. It may also decrease morbidity, postoperative hospital length of stay and thus cost ${ }^{[3]}$.

TEA has been established as a cornerstone in the perioperative care after thoracic and major abdominal surgery providing most effective analgesia. Beyond its analgesic properties, TEA's effects on the postoperative neurohumoural stress response, cardiovascular pathophysiology, and intestinal dysfunction have been in the focus of both clinical and experimental investigations for years. However, the use of TEA is related to specific complications and contraindications ${ }^{[4]}$.

Nowadays, the use of adjuvant drug with local anesthetic is essential as it prolongs the duration of action, gives better success rate and increases patient satisfaction ${ }^{[5]}$.

Ketamine is a selective antagonist of the NMDA receptor, an ionotropic glutamate receptor; it is used for postoperative pain

\section{The present study aims to:}

A) Detection of total dose of intravenous morphine consumption and time for the first request of rescue analgesia in the first 48 hours post operatively.

B) Assessment of visual analogue scale \& hemodynamic effects and side effects.

\section{Materials and Methods:}

This study was approved by the ethics committee of South Egypt Cancer Institute, Assiut University, Assiut, Egypt. It was prospectively registered in clinical trials (NCT03063671). After obtaining informed consent, adult women patients aged from 20 to 65 years old, ASA I or II were enrolled for the study. Before surgery, all the patients were instructed regarding benefits of thoracic epidural analgesia and taught how to evaluate their own pain intensity using VAS score from $0-10$ (where $0=$ no pain and $10=$ worst pain imaginable), and how to use PCA device (B_Braun ${ }^{\circledR}$ patient controlled analgesia. S. No: 267466. Melsungen Laboratory, AG: 60064, Germany). Eighty patients were randomly allocated to receive TEA at T4-5 interspace 15 minutes prior to induction of GA. Thoracic epidural catheter insertion was done 15 minutes prior to induction of general anesthesia in setting position and under strict aseptic precautions, the catheter was inserted management. Low doses of ketamine may reduce morphine use, nausea, and vomiting after surgery. It may also be used as an intravenous analgesic with opiates to manage otherwise intractable pain, particularly if this pain is neuropathic. It has the added benefit of counteracting spinal sensitization or wind-up phenomena experienced with chronic pain ${ }^{[6]}$.

There is evidence that ketamine may be a viable option for treatment of refractory cancer pain. Low-dose ketamine is sometimes used in the treatment of complex regional pain syndrome (CRPS) ${ }^{[7]}$.

Dexmedetomedine is an alpha 2 adrenergic receptor agonist, even ten times more selective than clonidine. Its highly lipophilic nature allows rapid absorption into the CSF and binding to $\alpha_{2}$-AR of spinal cord for its analgesic action. It prolongs the duration of both sensory and motor blockade induced by local anesthetics irrespective of the route of administration (e.g., epidural, caudal, or spinal). It enhances both central and peripheral neural blockade by local anesthetic ${ }^{[8 \& 9]}$.

in T4-T5 interspace, using a 16 gauge Tuohy epidural needle (B_Braun ${ }^{\circledR}$ set for continuous epidural analgesia. S.No 451 4017: Melsungen laboratory, AG: D-34209, Germany). Through a paramedian approach, after skin wheal of lidocaine local anesthetic $2 \%$. The epidural space was identified by the loss of resistance technique (using saline).The catheter was introduced approximately $4 \mathrm{~cm}$ into the epidural space, A $3 \mathrm{ml}$ test dose of $2 \%$ lidocaine with 1: 200,000 adrenaline was given after the placement of the epidural catheter to confirm its position. After a negative response to test dose, epidural analgesia was considered to be adequately working if there is decrease pin prick sensation at the expected dermatomal level and decrease in blood pressure. Patients received $12 \mathrm{ml}$ of hyperbaric bupivacaine $0.125 \%$ plus mixture of $0.3 \mathrm{mg} / \mathrm{kg}$ ketamine and $0.1 \mu \mathrm{g} / \mathrm{kg}$ dexmedetomedine (DK group) \& $12 \mathrm{ml}$ of hyperbaric bupivacaine $0.125 \%$ plus $0.5 \mathrm{mg} / \mathrm{kg}$ ketamine (K group) \&12 $\mathrm{ml}$ of hyperbaric bupivacaine $0.125 \%$ plus $1 \mu \mathrm{g} / \mathrm{kg}$ dexmedetomedine (D group) Or $12 \mathrm{ml}$ of hyperbaric bupivacaine $0.125 \%$ (C group).

General anesthesia was conducted after pre-oxygenation; IV induction was done by propofol $(1.5 \mathrm{mg} / \mathrm{kg})$ and fentanyl $1-2 \mu \mathrm{g} / \mathrm{kg}$. Tracheal intubation was performed after adequate neuromuscular blockade with cisatracurium $0.5 \mathrm{mg} / \mathrm{kg}$. Anesthesia was maintained by isoflurane 1-1.5 MAC, cisatracurium $0.03 \mathrm{mg} / \mathrm{kg}$ given when 
indicated. Patients were mechanically ventilated to maintain $\mathrm{ETCO}_{2}$ between 35-40 $\mathrm{mmHg}$. The inspired oxygen fraction $\left(\mathrm{FIO}_{2}\right)$ was 0.5 using oxygen-and-air mixtures. Heart rate, pulse oximetry, endtidal $\mathrm{CO} 2$, mean arterial blood pressure were measured and recorded at 5, 30, 60 minutes.

At the end of surgery neuromuscular block was reversed with neostigmine $0.05 \mathrm{mg} / \mathrm{kg}$ and atropine $0.02 \mathrm{mg} / \mathrm{kg}$ and trachea was extubated in the operating room when patients meet the following criteria: hemodynamic stability, adequate muscle strength, full consciousness, and adequate ventilation breathing rate: 10 to 30 breaths/min, $\mathrm{PaO}_{2} / \mathrm{FIO}_{2} \geq 80 / 0.4, \mathrm{PaCO}_{2}, 30$ to $45 \mathrm{mmHg}$ ).

- After full recovery patients were admitted to surgical ICU-for 48 hours for monitoring and

\section{Data analysis:}

The required sample size was calculated using Epi Info software version 7 (CDC, 2015) ®. Using post hoc power analysis with accuracy mode calculations with VAS as the primary objective, and therefore, it was estimated that minimum sample size of 19 patients in each study group would achieve a power of $80 \%$ to detect an effect size of 0.8 in the outcome measures of interest, assuming a type I

error of 0.05. All analyses were performed with the SPSS 20.0 ® software. Categorical variables were described by number and percent $(\mathrm{N}, \%)$, while continuous variables described by mean and standard deviation (Mean, SD). Mann-Whitney test was used to compare between two groups while Chi square test was used for qualitative data. The t-test was used to compare between continuous variables. $\mathrm{P}$-value $\quad 0.05$ considered statistically significant.

\section{Results:}

Among 96 patients who were screened for eligibility 80 patients were finally analyzed and were equally distributed in the four studied groups $(n=20)$ figure $I$.

There was no significant difference between the studied groups in the demographic or clinical data as shown in table I. No patient in DK group asked for analgesia at any time point of the study (48 hours). initiation of post-operative analgesia regimen. Using infusion through thoracic epidural catheter for 12 hours. On demand analgesia was given to patients using IV. morphine through PCA that was programmed to give 1 $\mathrm{mg} /$ press during 48 hours with a minimal lockout interval of 15 minutes with no background infusion. DK Group received infusion of mixture of bupivacaine $0.125 \%$ plus $2 \mu \mathrm{g} / \mathrm{ml}$ dexmedetomedine and ketamine $0.5 \mathrm{mg} / \mathrm{ml}$ in a rate of $5 \mathrm{ml} /$ hour. $\mathrm{K}$ group received infusion of mixture of bupivacaine $0.125 \%$ plus ketamine $0.5 \mathrm{mg} / \mathrm{ml}$ in a rate of $5 \mathrm{ml} /$ hour. D group received infusion of mixture of bupivacaine $0.125 \%$ plus dexmedetomedine $2 \mu \mathrm{g} / \mathrm{ml}$ in a rate of $5 \mathrm{ml} /$ hour while $\mathrm{C}$ group received infusion of bupivacaine $0.125 \%$ in a rate of $5 \mathrm{ml} /$ hour.

While 8 patients (40\%), $6(30 \%)$ and $9(45 \%)$ in groups $\mathrm{K}, \mathrm{D}$ and $\mathrm{C}$ respectively with highly significant difference $(\mathrm{P}<0.000)$ as shown in table II.

The mean time to first request of rescue analgesia was $(37.45 \pm 3.12 \mathrm{~h}),(19.43 \pm 1.78 \mathrm{~h})$ \& $(13.47 \pm 1.43 \mathrm{~h})$ in group $\mathrm{K}, \mathrm{D}, \mathrm{C}$ respectively with highly significant difference $(\mathrm{P}<0.000)$ as shown in table II.

The cumulative morphine IV-PCA was in group C $(8.33 \pm 1.63 \mathrm{mg})$ versus $(6.74 \pm 0.70$ $\mathrm{mg})$ and $(4.66 \pm 1.00 \mathrm{mg})$ in group $\mathrm{D}, \mathrm{K}$ respectively with $\mathrm{P}$ value $\mathrm{P}=0.646$ (table II).

-There was no significant differences between the studied groups in the mean of (VAS-R) and (VAS-M) immediate postoperative and at 2, 4, 6 hours postoperatively.

While at 12, 24, 36 hours there was significant reduction in the mean of VAS-R and VAS-M in group DK than the other groups $(\mathrm{K}, \mathrm{D}, \mathrm{C})$ as $P$ value $<0.000$ (figure II,III).

The mean of intraoperative mean arterial blood pressure showed highly significant difference between the studied groups at $5 \& 30$ minutes $(\mathrm{P}<0.000) \&(\mathrm{P}<0.005)$ respectively. While at 60 minutes intraoperatively showed no significant difference between the studied groups. There were highly significant differences between the studied groups immediate postoperatively and at 2, 4, 6, 12 hours postoperatively $\mathrm{P}<0.000$. There were no significant differences between the studied 
groups at 24, 36, 48 hours postoperative as shown in figure II.

Number of patients who developed nausea 9 $(45 \%)$ in the control group. $4(25 \%), 2(10 \%)$, $2(10 \%)$ in group D, K, DK respectively with highly significant difference $(\mathrm{P}<0.000)$ as shown in table II.

Itching was developed in 12 patients $(60 \%)$ in the control group, 5 (20\%) in D group, and no patients in K, DK groups as shown in table II.

In $\mathrm{D}$ group 15 patients (75\%) developed hypotension versus $4(20 \%)$ and $2(10 \%)$ in the $\mathrm{C}$ group and $\mathrm{K}$ group respectively and no patient of DK group at any time of the study (table II).

Bradycardia was developed in 5 patients (20\%), 12 (60\%) in D, C groups respectively with no patients in $\mathrm{K}$, DK groups with highly significant difference $(\mathrm{P}<0.000)$ as shown in table II.

\section{Discussion:}

Our study found that combination of thoracic epidural dexmedetomedine and ketamine provided an effective and superior postoperative analgesia, prolonged the time to first request of rescue analgesia, and reduced the total consumption of PCA morphine, without serious side effects compared to either drug alone.

Breast cancer is the most common cancer diagnosed in Egyptian women. Breast surgery is one of the most common forms of surgery conducted in hospitals; even relatively

minor breast surgery can be associated with significant postoperative pain ${ }^{[10 \& 11]}$.

Regional anesthesia techniques have provided better quality of acute pain control and subsequently less chronic pain. Rietman reported successful perioperative management with TEA in a diagnosed case of carcinoma of breast with severely compromised pulmonary function due to COPD undergoing MRM ${ }^{[12] \text {. }}$

TEA with use of low dose of local anesthetic helps to preserve respiratory function. Bashandy et al, reported successful anesthetic management for bilateral mammoplasty with TEA in a Klippwl-Feil syndrome with difficult airway ${ }^{[13]}$
A recent meta-analysis about pulmonary effects of TEA showed decline in postoperative pulmonary complications like pneumonia due to earlier ambulation, reduced opioids consumption and improved compliance of patient for chest physiotherapy. [14].

Diaphragmatic function remains unimpeded as far as the neuraxial blockade remains below the cervical emergence of phrenic nerves (C3C5). So, it is extremely important to watch level of epidural block because if level reaches above C6, Horner's syndrome may develop. If level goes up to C4, patient's voluntary efforts of respiration stop and might require ventilatory support. Site of puncture decides the cephalad extension of block. But the higher the placement site, the lesser is cephalad spread and more caudal spread, hence we selected site T4-5 ${ }^{[15]}$

Recently, Wahba and Kamal found that Pecs block reduced postoperative morphine consumption in the first 24 hours and pain scores in the first 12 hours postoperatively following MRM in comparison to PVB. This agrees with our findings, where the VAS values in the four groups after receiving TEA were less than 3 for the whole follow-up period of 48 hours ${ }^{[16]}$.

Bouman et al, stated that single dose TEA for oncology mastectomies with axillary clearance has many advantages when compared with general anesthesia. TEA has been shown to decrease adverse perioperative cardiac events, morbidity and mortality after cardiac and non-cardiac major surgery ${ }^{[17]}$

Ketamine decreases postoperative pain intensity up to 48 hours, decreases cumulative 24-hour morphine consumption, and delays the time to first request of rescue analgesic therapy. It also improves analgesia in cancer pain that is refractory to opioid therapy, but there is a high incidence of dysphoria and sedation ${ }^{[18]}$

The specific role of ketamine in preventing opioid induced hyperalgesia $(\mathrm{OIH})$ is also of interest: whether its site of action is in the spinal cord (where central sensitization involving the NMDA receptor occurs) or in higher centers does require further study ${ }^{[19]}$ 
In a chronic pain, low-dose intravenous (IV) ketamine seems to reduce peripheral neuropathic and spinal cord injury pain, fibromyalgia symptoms, lower limb ischemic rest pain, and chronic phantom limb pain. In addition, there are case reports and pilot studies suggesting beneficial effects of the $S$ $(+)$ isomer in complex regional pain syndromes (CRPS) ${ }^{[20]}$

The addition of ketamine to a local anesthetic in peripheral or neuraxial anesthetic and analgesic techniques improves or prolongs pain relief with a decrease in drug-related side effects mainly because the required drug doses are reduced. These effects may be explained by blockade of central and peripheral NMDA receptors and/or an anti-nociceptive action complementary to that of the other drugs used [21]

Rahimzadeh et al, compared thoracic epidural ketamine and morphine in patients submitted to mastectomy and demonstrated that Ketamine had adequate profile to be used in upper thoracic epidural anesthesia being heamodynamically safe and effective, with better performance to control the postoperative pain as compared to morphine, generating less analgesic consumption as well as lower incidence of adverse effect ${ }^{\text {[22] }}$

Other possible peripheral mechanisms of action of ketamine include binding to multiple opioid receptors (ORs); binding to monoamine transporters; binding to muscarinic and nicotinic cholinergic receptors and inhibition of function ; binding to D2 and 5-HT2 receptors ; inhibition of ion channels $(\mathrm{Na}+\mathrm{Ca} 2+, \mathrm{K}+)$; decreased activation and migration of microglia ; and finally, inhibition of production of inflammatory mediators ${ }^{[23]}$

Lashgarinia et al, concluded that adding ketamine in a dose of $2 \mathrm{mg} / \mathrm{kg}$ to lidocaine 5 $\mathrm{mg} / \mathrm{kg} 1.5 \%$ in ultrasound-guided brachial plexus block could decrease the postoperative pain and need for analgesia most probably due to the local anesthetic effect of ketamine at the level of surgical trauma ${ }^{[24]}$

Ketamine has an anti-inflammatory effect that significantly inhibits the early postoperative inflammatory response. It can act at different levels of inflammation, interacting with inflammatory cell recruitment, cytokine production, and inflammatory mediator regulation $^{\text {[25] }}$

The effect of ketamine is more likely to occur locally in an inflamed tissue, but not at the level of a nerve plexus distant from the surgical site. Its effects are not specific to a certain type or dose of local anesthetic agents [26].

In our study, ketamine added to bupivacaine prolonged the time to first request of analgesia and reduced the total amount of morphine consumption in comparison to bupivacaine alone.

Dexmedetomedine, an imidazole compound, is the pharmacologically active dextro-isomer of medetomedine that displays specific and selective $\alpha 2$-adrenoceptor agonist. It acts by binding to pre-synaptic C-fibers and post synaptic dorsal horn neurons; they produce analgesia by depressing the release of C-fiber transmitters and hyperpolarization postsynaptic dorsal horn neurons ${ }^{[27] .}$

Al-Mustafa et al, studied the effect of intrathecal dexmedetomedine $5 \mu \mathrm{g}$ and $10 \mu \mathrm{g}$ with bupivacaine in urological procedures and found that dexmedetomedine prolongs the duration of spinal anesthesia in a dosedependent manner ${ }^{[27]}$.

Shukla et al, compared dexmedetomedine with magnesium sulfate used as an adjuvant to bupivacaine for both lower abdominal and lower limb procedures and concluded that the onset of anesthesia was rapid and of prolonged duration in the dexmedetomidine group compared to magnesium sulfate. Mohamed also concluded that intrathecal $5 \mu \mathrm{g}$ dexmedetomedine improves the quality and the duration of postoperative analgesia and also provides an analgesic sparing effect in patients undergoing major abdominal cancer surgery [28\&29].

Eskandar et al, used dexmedetomidine as a novel adjuvant to epidural steroids to control pain in patients with failed back surgery syndrome (FBSS). This study showed that the addition of dexmedetomidine to epidural steroids results in superior pain control and this was evidenced by a decrease in the total 
required dose of NSAID and a better life style [30].

The hypotensive effect of dexmedetomidine results from stimulation of $\alpha 2$-inhibitory neurons in the medullary vasomotor center (nucleus reticularis lateralis) of the brainstem, which leads to a reduction in norepinephrine release and sympathetic nerve outflow from the CNS to the peripheral tissues. Bradycardia is caused by an increase in vagal tone resulting from central stimulation of parasympathetic outflow, as well as a reduced sympathetic drive ${ }^{[31]}$.

Abdel-Baky et al, stated that the combination of $5 \mu \mathrm{g} / \mathrm{kg}$ dexmedetomedine and $0.1 \mathrm{mg} / \mathrm{kg}$ of ketamine co-administered with spinal bupivacaine in addition to general anesthesia in patients undergoing lower abdominal cancer surgery provided superior postoperative analgesia, prolonged the time to first request of rescue analgesics, and reduced the mean total consumption of PCA morphine in the first 24 hours post- operative without serious side effects compared to patients who received either drug alone. This may be explained by both the low dose of ketamine used, and its combination with dexmedetomedine ${ }^{[32]}$.

In our study, there was a statistically significant reduction in mean arterial blood pressure intra-operative in the dexmedetomedine D group and the combined ketamine and dexmedetomedine DK group when compared with the ketamine $\mathrm{K}$ group. In the postoperative period there were no significant differences between groups in postoperative mean arterial blood pressure.

Our results support that the addition of dexmedetomedine to ketamine improves the analgesic efficacy and reduces possible side effects of both of them. The administered ketamine as an adjuvant to bupivacaine at a dose of $0.1 \mathrm{mg} / \mathrm{kg}$ alone or combined with dexmedetomedine $5 \mu \mathrm{g} / \mathrm{kg}$ was not associated with serious central or other side effects, but results in better outcome, This explained by the low dose of both drugs.

\section{Conclusion:}

The addition of dexmedetomedine $1 \mu \mathrm{g} / \mathrm{kg}$, ketamine $0.3 \mathrm{mg} / \mathrm{kg}$ to bupivacaine $0.125 \%$ in TEA in patients undergoing modified radical

mastectomy improves the quality and the duration of analgesia and also provides hemodynamic stability and an analgesic sparing effect with no serious side effects.

\section{Reference:}

1- Vilholm OJ, Cold S, Rasmussen L, Sindrup SH. The post mastectomy pain syndrome: An epidemiological study on the prevalence of chronic pain after surgery for breast cancer. $\mathrm{Br} \mathbf{J}$ Cancer. 2008. 99:604-610.

2- Ravi PR, Jaiswal P, Capt PR. Thoracic epidural analgesia for breast oncological procedures: A better alternative to general anesthesia J Mar Med Soc 2017;19:91-5.

3- Ahmed AM, Ali H, Helal O, Sobhi T (2017) Comparative Study between Continuous Thoracic Epidural vs. Thoracic Spinal Anesthesia in Breast Surgery. J Pain Relief 6: 292.doi:10.4172/2167-0846.1000292.

4- Sudha Shah, Sch. J. Study of Breast Surgery under Thoracic

Epidural Analgesia. App. Med. Sci., June 2016; 4(6F):2244-2247

5- Macintyre PE, Scott DA, Schug SA, et al. Acute pain management: scientific evidence [Systematic reviews and meta-analyses]. 3rd edition. 2010. Accessed June 25, 2014.

6- Dong, C; Anand, KJS (June 2013). " Developmental neurotoxicity of ketamine in pediatric clinical use". Toxicology letters. 220 (1): 53-60. doi:10.1016/j.toxlet.2013.03.030. PMID 23566897.

7- Morgan, CJA; Muetzelfeldt, L; Curran, HV (2009). "Consequences of chronic ketamine self-administration upon neurocognitive function and psychological wellbeing: A 1-year longitudinal study". Addiction. 105 (1): 
121-33. doi:10.1111/j.13600443.2009.02761.x. PMID 1991-9593.

8- Wagner DS , Brummett CM. Dexmedetomidine: As safe as safe can be. Semin Anesth Peri -op. Med Pain.2006; 25:77-83.

9-Yoshitomi T, Kohjitani A, Maeda S, Higuchi H, Shimada M, Miyawaki T. Dexmedetomidine enhances the local anesthetic action of lidocaine via an alpha-2A adrenoceptor. Anesth Analg. 2008;107:96-101.

10- Exadaktylos AK, Buggy DJ, Moriarty DC, Mascha E, et al. Can anesthetic technique for primary breast cancer surgery affect recurrence or metastasis? Anesthesiology 2006; 105:660.

11- Ahmed H Othman, MD, Ahmad M Abd El-Rahman, MD, and Fatma Adel El Sherif. Efficacy and Safety of Ketamine Added to Local Anesthetic in Modified Pectoral Block for Management of Postoperative Pain in Patients Undergoing Modified Radical Mastectomy Pain Physician 2016; 19:485-494 ISSN 1533-3159.

12- Rietman JS, Dijkstra PU, Debreczeni R, et al. Impairments, disabilities and health related quality of life after treatment for breast cancer: a follow-up study $\mathbf{2 . 7}$ years after surgery. Disabil Rehabil 2004; $26: 78$.

13- Bashandy GM, Abbas DN. Pectoral nerves I and II blocks in multimodal analgesia for breast cancer surgery. Reg. Anesth. Pain Med 2015; 40:68-74.

14- Sittl R, Irnich D, Lang PM. Update on preemptive analgesia: Options and limits of preoperative pain therapy [in German].Anesthetist 2013; 62:789-796.

15- Holman SJ, Bosco RR, Kao TC, et al. What constitutes an effective but safe initial dose of lidocaine to test a thoracic epidural catheter? Anesth, Analg. 2001; 93(3):749-54

16- Wahba SS, Kamal SM. Thoracic paravertebral block versus pectoral nerve block for analgesia after breast surgery. Egyptian Journal of Anaesthesia2014; 30:129-135.

17- Bouman EA, Theunissen M, Bons SA, van Mook WN, Gramke HF, van Kleef M, Marcus MA. Reduced incidence of chronic postsurgical pain after epidural analgesia for abdominal surgery. Pain Practice 2013 doi: 10.1111/papr.12091.

18- Colvin L.A, Fallon MT. Opioid-induced hyperalgesia: Low-dose ketamine does work for some orthopaedic problems already.BJA 2010; 104: 660-661.

19- Kiefer RT, Rohr P, Ploppa A, DieterichHJ, Grothusen J, Koffler S, Altemeyer KH, Unertl K, Schwartzman RJ. Efficacy of ketamine in anesthetic dosage for the treatment of refractory complex regional pain syndrome: An open-label phase II study. Pain Med 2008; 9:11731201.

20- Talbot H, Hutchinson SP, Edbrooke DL,Wrench I, Kohlhardt SR. Evaluation of a local anesthesia regimen after mastectomy Anaesthesia 2004; 59:664667.

21- Panjabi N, Prakash S, Gupta P, GogiaAR. Efficacy of three doses of ketamine with bupivacaine for caudal analgesia in pediatric inguinal herniotomy. Reg. Anesth Pain Med 2004; 29:28-31.

22- Rahimzadeh P, Faiz SH, Ziyaeifard M,Niknam K. Effectiveness of adding ketamine to ropivacaine infusion via femoral nerve catheter after knee anterior cruciate ligament repair Res Med Sci 2013; 18:632-636.

23- De Kock M, Loix S, Lavand'homme P. Ketamine and peripheral inflammation CNS NeurosciTher2013; 19:403-410.

24- Lashgarinia M, Naghibi K, HonarmandA, Safavi M, Mehdi K. Effect of ketamine as an adjuvant in ultrasound guided supraclavicular brachial I plexus block: A clinical trial double-blind randomized study. Adv Biomed Res 2014; 3:232. 
25- Loix S, De Kock M, Henin P. The antiinflammatory effects of ketamine: State of the art.ActaAnaesthesiol Belg 2011;62 :47-58.

26- Khezri MB, Ghasemi J, Mohammadi N. Evaluation of the analgesic effect of ketamine as an additive to intra-thecal bupivacaine in patients undergoing cesarean section Taiwan 2013;51:155160.

27- Al-Mustafa MM, Abu-Halaweh SA, AloweidiAS, Aloweidi AS, Murshidi MM, Ammari BA, Awwad ZM, AlEdwan. Effect of dexmedetomedine added to spinal bupivacaine for urological procedures.2009; 31:154170.

28- Shukla D, Verma A, Agarwal, PandeyHD, Tyagi C. Comparative study of intrathecal dexmedetomidine with intrathecal magnesium sulfate used as adjuvants to bupivacaine. J AnesthesiolClinPharmacol2011; 27:495499

29- Mohamed AA, Fares KM, Mohamed SAE. Efficacy of intrathecally administered dexmedetomidine

versus dexmedetomidine with fentanyl in patients undergoing major abdominal cancer surgery. Pain Physician 2012; 15:339-348.

30- Ashraf Eskander, Sadek Abdel Maseeh, Effect of dexmedetomedine on lumbar epidural injection for failed back surgery syndrome, department of anesthesia,ICU and pain therapy, faculty of medicine,Menoufyia university, shibin El-Koom 3251, Egypt, Vol.16, July,2016,pp.629-639.

31- Talke P, Chen R, Thomas B, AggarwallA, Gottlieb A, Thorborg P, Heard S,Cheung A, Son SL, Kallio A. The hemodynamic and adrenergic effects of perioperative dexmedetomidine infusion after vascular surgery. AnesthAnalg2000; 90:834-839.

32- Sahar Abdel-Baky Mohamed, Ahmed Mohamed Abd El-Rahman, and Khaled Mohamed Fares. Intrathecal dexmedetomedine, ketamine and their combination added to bupivacaine for postoperative analgesia in major abdominal cancer surgery, pain physician, NULL, Vol.19, July,2016, pp.829-839. 
Page 42 of 46

\section{Results}

Table I. Patients demographics and clinical characteristics:

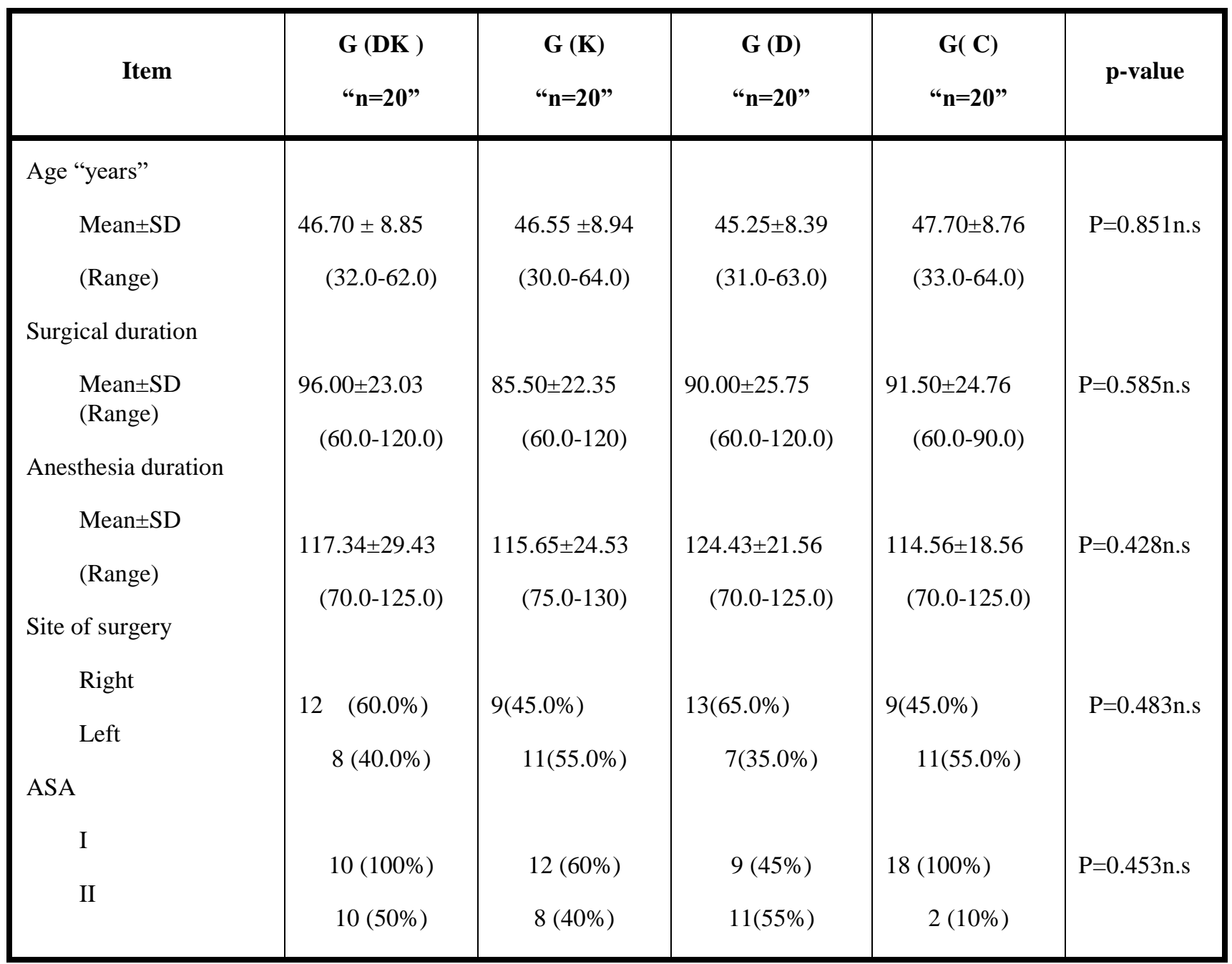

-Data are expressed as mean $\pm \mathrm{SD}$ and range.

-ASA: American society of anesthiologists physical status.

Statistically insignificant difference $(\mathrm{P}>0.05)$.

*Statistically significant difference $(\mathrm{P}<0.05)$.

**Statistically moderate significant difference $(\mathrm{p}<0.01)$.

***Statistically high significant difference $(\mathrm{p}<0.000)$. 
Page 43 of 46

Table II. Consumption of intravenous patient controlled morphine analgesia in the first $\mathbf{4 8}$ hours post-operatively and post-operative side effects:

\begin{tabular}{|l|c|c|c|c|c|}
\hline \multicolumn{1}{|c|}{ Item } & $\begin{array}{c}\mathbf{G}(\mathbf{D K}) \\
\mathbf{n = 2 0}\end{array}$ & $\mathbf{G}(\mathbf{K}) \mathbf{n = 2 0}$ & $\begin{array}{c}\mathbf{G}(\mathbf{D}) \\
\mathbf{n = 2 0}\end{array}$ & $\begin{array}{c}\mathbf{G}(\mathbf{C}) \\
\mathbf{n = 2 0}\end{array}$ & P value \\
\hline - No. of pts. & 0 & $6(30.0 \%)$ & $8(40.0 \%)$ & $9(45.0 \%)$ & $\mathrm{P}<0.000^{* * * *}$ \\
- total PCA morphine (mg) & 0 & $4.66 \pm 1.00$ & $6.74 \pm 0.70$ & $8.33 \pm 1.63$ & $\mathrm{P}=0.646 \mathrm{n} . \mathrm{s}$ \\
- 1 $^{\text {st. request }}$ & 0 & $37.45 \pm 3.12$ & $19.43 \pm 1.78$ & $13.47 \pm 1.43$ & $\mathrm{P}<0.000^{* * *}$ \\
& & & & & \\
Side effect & & & & & \\
- Nausea & $2(10 \%)$ & $2(10 \%)$ & $4(25 \%)$ & $9(45 \%)$ & $\mathrm{P}<0.000^{* * *}$ \\
- Vomiting & 0.0 & 0.0 & 0.0 & 0.0 & - \\
- Hypotension & 0.0 & $2(10 \%)$ & $15(75 \%)$ & $4(20 \%)$ & $\mathrm{P}<0.000^{* * *}$ \\
- Bradycardia & $2(10 \%)$ & 0.0 & $5(20 \%)$ & 0.0 & $\mathrm{P}<0.000^{* * *}$ \\
- Dizziness & 0.0 & 0.0 & 0.0 & 0.0 & -- \\
- Itching & 0.0 & 0.0 & $5(20 \%)$ & $12(60 \%)$ & $\mathrm{P}<0.000^{* * * *}$ \\
- Arrhythmia & 0.0 & 0.0 & 0.0 & 0.0 & -- \\
- Postop. radicular pain & 0.0 & 0.0 & 0.0 & 0.0 & -- \\
- Epidural hematoma & 0.0 & 0.0 & 0.0 & 0.0 & - \\
- Epidural abscess & 0.0 & 0.0 & 0.0 & 0.0 & - \\
- Pneumothorax & 0.0 & 0.0 & 0.0 & - \\
- Respiratory depression & 0.0 & 0.0 & 0.0 & - \\
\hline
\end{tabular}

Data are expressed as number of patients and percentage .

Statistically insignificant difference $(\mathrm{P}>0.05)$.

*Statistically significant difference $(\mathrm{P}<0.05)$.

**Statistically moderate significant difference $(\mathrm{p}<0.01)$.

***Statistically high significant difference $(\mathrm{p}<0.000)$. 
Figure I. Participate flow diagram.

\section{Assessment for eligibility $(n=96)$}

Enrollment

Allocation

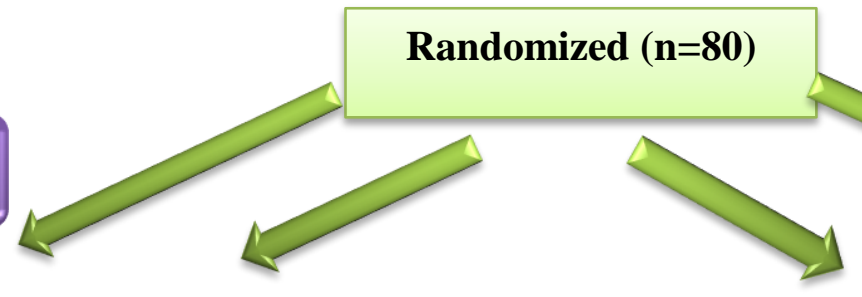

\section{D group}

- Allocated for intervention $(n=20)$

- Received allocated intervention $(\mathrm{n}=20)$

- Did not receive allocated intervention $(\mathrm{n}=0)$

\section{Excluded (n=16)}

- Not meeting inclusion criteria $(\mathrm{n}=9)$

- Decline to participate $(n=7)$
- Allocated for intervention $(n=20)$

- $\quad$ Received allocated intervention $(\mathrm{n}=33)$

- Did not receive allocated intervention $(\mathrm{n}=0)$
- Allocated for intervention $(\mathrm{n}=20)$

- Received allocated intervention $(\mathrm{n}=20)$

- Did not receive allocated intervention $(\mathrm{n}=0)$

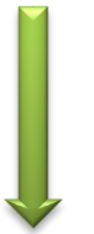

- Continue follow up $(n=20)$

- Lost in follow up $(\mathrm{n}=0)$

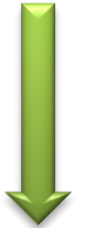

- Continue follow up $(\mathrm{n}=20)$

- Lost in follow up $(\mathrm{n}=0)$

\section{C group}

- Allocated for intervention $(n=20)$

- $\quad$ Received allocated intervention $(n=20)$

- Did not receive allocated intervention $(n=0)$
- Continue follow up $(\mathrm{n}=20)$

- Lost in follow up $(\mathrm{n}=0)$

\section{Analysis}

- analyzed $(\mathrm{n}=20)$

- Excluded from analysis $(\mathrm{n}=0)$
- analyzed $(\mathrm{n}=20)$

- Excluded from analysis $(\mathrm{n}=0)$
- analyzed $(n=20)$

- Excluded from analysis $(n=0)$
- Continue follow up $(\mathrm{n}=20)$

- Lost in follow up $(\mathrm{n}=0)$

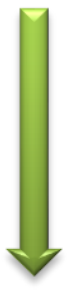

- analyzed $(\mathrm{n}=20)$

- Excluded from analysis $(\mathrm{n}=0)$ 
Figure II. Mean Arterial blood Pressure (MAP) data.

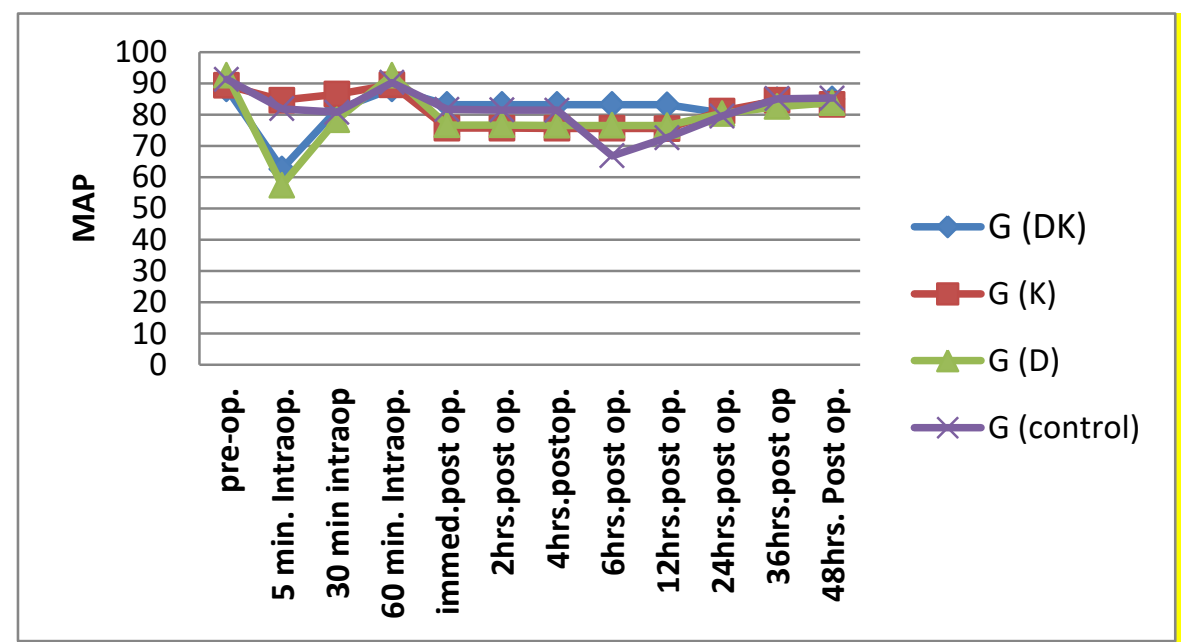

-Data are expressed as mean \pm SD and range.

Statistically insignificant difference $(\mathrm{P}>0.05)$.

*Statistically significant difference $(\mathrm{P}<0.05)$.

**Statistically moderate significant difference $(\mathrm{p}<0.01)$.

$* * *$ Statistically high significant difference $(\mathrm{p}<0.000)$.

Figure III .Visual Analogue Scale data at rest (VASR) .

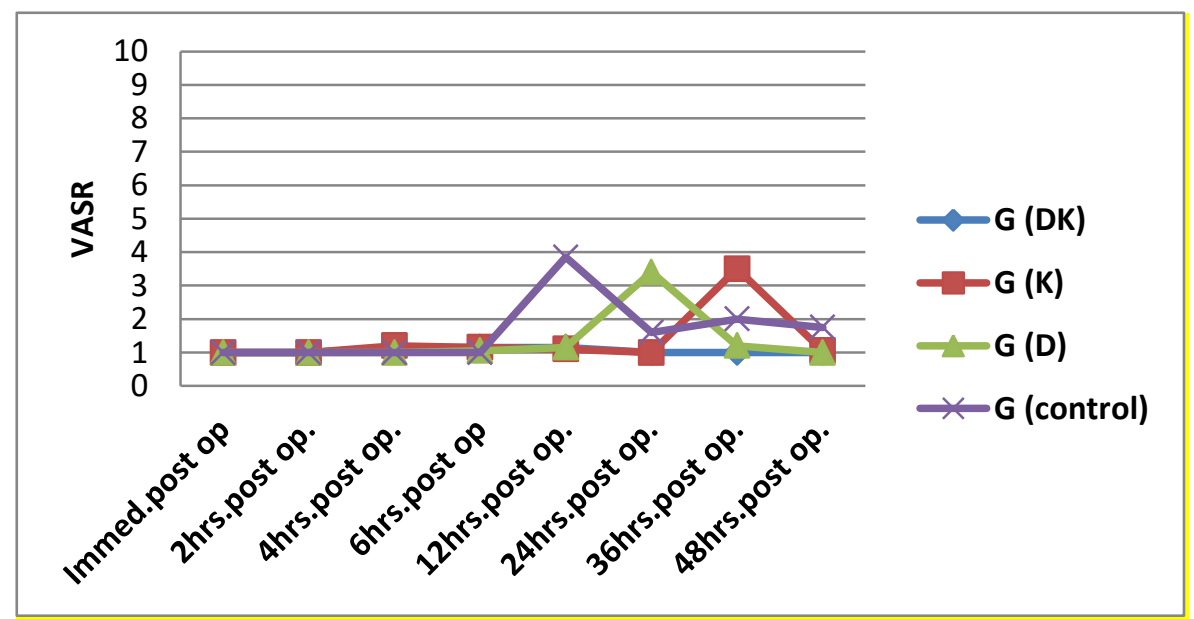

-Data are expressed as mean $\pm \mathrm{SD}$ and range.

Statistically insignificant difference $(\mathrm{P}>0.05)$.

*Statistically significant difference $(\mathrm{P}<0.05)$.

**Statistically moderate significant difference $(\mathrm{p}<0.01)$.

***Statistically high significant difference $(\mathrm{p}<0.000)$. 
Page 46 of 46

Figure IV. Visual analogue scale data at movement (VASM).

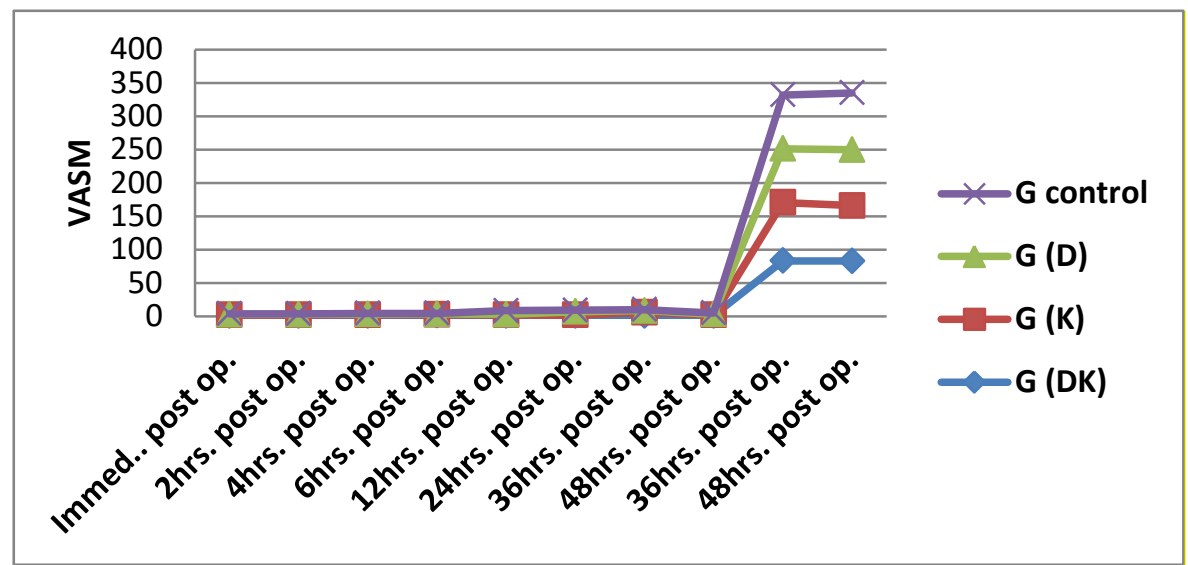

-Data are expressed as mean \pm SD and range.

Statistically insignificant difference $(\mathrm{P}>0.05)$.

*Statistically significant difference $(\mathrm{P}<0.05)$.

**Statistically moderate significant difference $(\mathrm{p}<0.01)$.

***Statistically high significant difference $(\mathrm{p}<0.000)$. 